\title{
Urethral Cancer pNO TNM Finding v8
}

National Cancer Institute

\section{Source}

National Cancer Institute. Urethral Cancer pNO TNM Finding v8. NCI Thesaurus. Code C140454.

Urethral cancer with no regional lymph node metastasis. (from AJCC 8th Ed.) 